\title{
Advantages and Potential Challenges of Data management in E- Maintenance
}

\section{Purpose}

The purpose of this research paper is firstly to understand data management challenges in EMaintenance systems from a holistically viewpoint through summarizing the earlier scattered research in the field, and secondly to present a conceptual approach for addressing these challenges in practice.

\section{Design/Methodology/Approach}

The study is realized as a combination of a literature review and by the means of analyzing the practices on an industry leader in manufacturing and maintenance services.

\section{Findings}

This Research provides a general understanding over data management challenges in EMaintenance and summarizes their associated proposed solutions. In addition, this paper lists and exemplifies different types and sources of data which can be collected in E-Maintenance, across different organizational levels. Analyzing the data management practices of an E-Maintenance industry-leader provides a conceptual approach to address identified challenges in practice

\section{Research limitations/implications (if applicable)}

Since this paper is based on studying the practices of a single company, it might be limited to generalize the results. Future research topics can focus on each of mentioned data management challenges and also validate the applicability of presented model in other companies and industries.

\section{Practical Implications (if applicable)}

Understanding the E-Maintenance related challenges helps maintenance managers and other involved stakeholders in E-Maintenance systems to better solve the challenges.

\section{Originality/Value}

The so-far literature on E-Maintenance has been studied with narrow focus to data and data management in E-Maintenance appears as one of the less-studied topics in the literature. This research paper contributes to E-Maintenance by highlighting the deficiencies of the discussion surrounding the perspectives of data management in E-Maintenance by studying all common data management challenges and listing different types of data which need to be acquired in EMaintenance systems.

\section{Keywords}

E-Maintenance, Maintenance Data, Data Management, Data Quality, Data Acquisition 


\section{Introduction}

E-Maintenance is an interdisciplinary approach to asset management, which thanks to Information and Communication Technologies (ICTs), integrates and synchronizes various maintenance and reliability functions, such as monitoring, diagnosis, prognosis and decision processes, and delivers asset information where and when needed (Muller et al., 2008, Holmberg et al. 2010). Gathering all maintenance strategies in one place, E-Maintenance incorporates maintenance with manufacturing and overall business operations by establishing an overlaying function over different organizational structures and links isolated processes into one transparent, integrated, and value-adding system (Hausladen and Bechheim, 2004, Holmberg et al. 2010).

E-Maintenance creates a platform for sharing data all over the enterprise, increases the process efficiency and results in more cost-effective decisions (Jordan and Ellen, 2009). In E-Maintenance systems, it is easier to acquire data from different sources, process larger data sizes and increase data usability to assure information quality for a more productive maintenance system (Candell et al., 2009; Muller et al., 2008). E-Maintenance especially plays a key role in those cases where delivering different information to various stakeholders is essential (Kour et al., 2014).

Integration of different systems, however, makes E-Maintenance more complicated and higher volumes of data must be generated to assure availability of overall system (Karim et al., 2009). An E-Maintenance system involves a wide variety of data including maintenance data, product data and operational data that all are gathered from heterogeneous sources, requiring to be processed and merged, in order to optimize maintenance decisions (Aljumaili et al., 2015, Kobbacy et al. 2008). Moreover, in E-Maintenance, data is gathered for versatile purposes such as planning, observing and assessing equipment's condition and to support different maintenance processes (Murthy et al., 2015). Collecting a wide variety of data for the purpose of E-Maintenance involves data management challenges, which have not been studied adequately in academia before.

According to Aboelmaged (2015), E-Maintenance research has flourished between 2010 and 2012. The so-far published articles on E-Maintenance can be categorized in three main classes: 1) Articles which research E-Maintenance concept from different perspectives (e.g. Aboelmaged (2015), Jantunen et al., (2010), Muller et al., (2008), Levrat et al. (2008)). 2) Articles which propose platforms for implementing E-Maintenance (e.g. Verma et al., (2010), Bangemann et al., (2006), Han and Yang (2006), Hausladen and Bechheim (2004)). 3) Articles which study E-Maintenance from data and information management perspective (e.g. Aljumaili et al., (2015), Kour et al., (2014), Campos (2014), Tretten and Karim (2014), Karim et. al., (2009)). Regardless of the variety of previous discussion, particularly the discussion on data and information management in the E-Maintenance context has been lacking.

The aim of this research is two-fold: to understand data management challenges in E-Maintenance systems from a holistically viewpoint through summarizing the earlier scattered research in the field, and to present a conceptual approach for addressing these challenges in practice. The study is based on a literature review and analyzing the practices of an E-Maintenance organization that is a global market-leader, in manufacturing and maintenance services.

The remainder of this paper is organized as follows: Section 2 discusses the research methodology. Section 3 contains literature review in the context of data management challenges in E-Maintenance. Section 4 presents the analysis of the selected company in order to validate the findings from literature and map the current system. Section 5 discusses the results and proposes an improved future-state, followed by scientific and managerial implications. Finally section 7 concludes the paper. 


\section{Research Method}

The ultimate objective of this research is to discover data management challenges in E-Maintenance systems. To achieve this goal, A literature review was performed to summarize earlier diverse research in E-Maintenance field in context of data management. Literature review consists of an extensive review of peer-reviewed journal, scientific conference papers as well as textbooks, dealing with Maintenance and E-Maintenance in general and data management in particular.

Studied papers were selected through an electronic search in accredited databases, such as ScienceDirect, Emeralds and SpringerLink. Keywords used for electronic search include "EMaintenace data", "maintenance data", "condition monitoring data", "data management in Emaintenance", "ICT technologies in maintenance". In addition to peer-reviewed journal and scientific conference papers, a number of maintenance and E-Maintenance- related textbooks were also studied.

In addition to reviewing and summarizing E-Maintenance literature, the data management practices of a global E-Maintenance organization were studied in order to present a conceptual framework for addressing data management challenges in industrial context. Figure 1 shows the initial understanding of the research process.

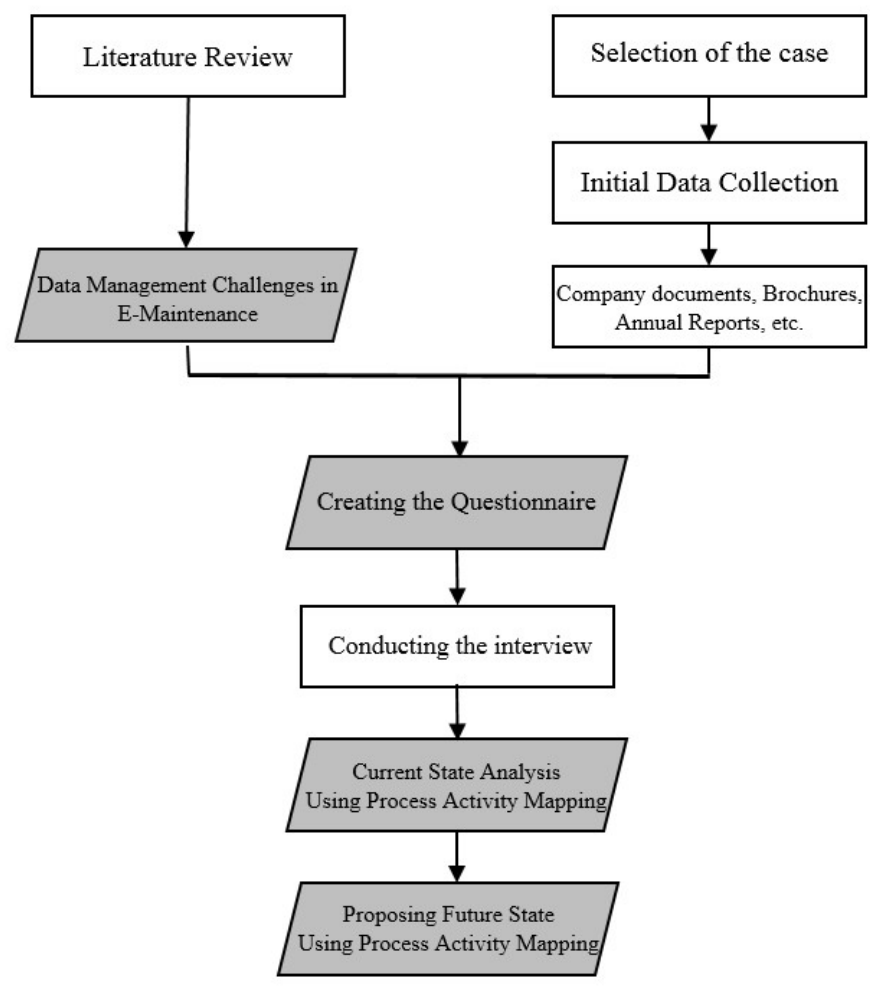

Figure 1. Initial Understanding of the Research Process.

\subsection{Selection of an E-Maintenance Organization to study}

In order to select the right industrial organization to analyze data management in E-Maintenance , two major factors were considered: 1) the size of the organization and 2) the criticality of EMaintenance for the company. According to these criteria, an industry-leading company which manufactures industrial machines and offers maintenance services to a large group of customers from various industries such as manufacturing, process and harbors was selected. 
The selected company manufactures industrial equipment through a set of internationally-known brands. In addition, the company has about 600 different service locations in 50 countries world-wide and offers a variety of maintenance and modernization services. It owns the most extensive service network in its industry, covering 450,000 units, where most of them have not been manufactured by the company itself. Industrial internet is one of the main building blocks, on which the company has been founded. The novel E-Maintenance services, offered by the company constitutes $55 \%$ of its personnel and $44 \%$ of its annual turnover.

\subsection{Data Collection}

Data triangulation increases the validity of the findings and helps researcher to better perceive the complex systems. Therefore, in order to cross-verify and validate the collected data, Data Source Triangulation and Methodology Triangulation have been utilized. In order to gain an inclusive and deep insight on data management in E-Maintenance systems, data about the E-Maintenance system of the studied company, has been collected in different forms, including product brochures, service catalogues, annual reports and company's confidential materials, Along with analyzing the content of acquired data, an extensive qualitative research was conducted, aiming to understand the common data management challenges in E-Maintenance. In Methodology Triangulation, multiple methods have been implemented to collect data, such as reading documents, field observations, creating questionnaires and conducting interviews.

Identifying data management challenges via literature review and acquiring versatile data through different data collection methods, provide a good basis for the interview part.Head of Product Lifecycle Management (PLM) in a leading E-Maintenance organization was interviewed in person and afterwards an electronic questionnaire was distributed in PLM department consisting 50 people. Questionnaire contained open questions, whereas the interviewees were free to share their knowledge and experience anonymously about the company's E-Maintenance system or even provide complementary information, in case not covered by the questionnaire."

Based on data collection and interview, current E-Maintenance platform of studied company is visualized by using Process Activity Mapping tool. The data management challenges and improvement needs have been argued in discussion part and finally the future-state is proposed accordingly.

\section{Literature Review}

Embracing different processes within and outside of an organization, high volumes of data need to be collected, stored, processed and shared in E-Maintenance systems. Different data management challenges are, however, present which need to be overcome in order to make timely and appropriate maintenance-related decisions. Table 1. Summarizes the most common data management challenges along with E-Maintenance implementation.

Table 1. Common Data Management Challenges in E-Maintenance

\begin{tabular}{lll}
\hline Challenges & Description & Contributors \\
\hline
\end{tabular}




\begin{tabular}{lll}
\hline Data Acquisition & $\begin{array}{l}\text { Process of collecting various types of E- } \\
\text { Maintenance data from objective and subjective } \\
\text { sources }\end{array}$ & Wandt et al., (2012), Murthy et al., \\
& (2015), Jardine et al., (2006), \\
& Aljumaili et al., (2015), Tretten et al., \\
& (2014), Campos, (2009), Karim et al., \\
& (2016), March and Scudder, (2017)
\end{tabular}

\begin{tabular}{lll}
\hline Rapid Information & $\begin{array}{l}\text { Bi-directional and seamless flow of information } \\
\text { among all stakeholders involved in different }\end{array}$ & Iung (2003), Arnaiz et al., (2009), \\
& processes & Lee, (2003), Candell et al., (2009). \\
& & Campos, (2009), Hausladen and \\
& Bachheim, (2004), Lee et al., (2006), \\
& Zhang et al., (2003), Wan et al., \\
(2016), Bousdekis et al., (2017)
\end{tabular}

\begin{tabular}{|c|c|c|}
\hline Data Quality & $\begin{array}{l}\text { Collecting relevant, fit-for-use data from all } \\
\text { stakeholders in E-Maintenance system and } \\
\text { cleaning data from errors }\end{array}$ & $\begin{array}{l}\text { Aljumaili et al., (2015), Jardine et al., } \\
\text { (2006), Tretten et al., (2014), Jantunen } \\
\text { et al., (2010), Tsang et al., (2006), Lin } \\
\text { et al., (2006), Bergquist and } \\
\text { Söderholm (2014), Karim et al., } \\
\text { (2016), }\end{array}$ \\
\hline $\begin{array}{l}\text { Voluminous and } \\
\text { Heterogeneous Data }\end{array}$ & $\begin{array}{l}\text { Dealing with large volumes of E-Maintenance } \\
\text { data from heterogeneous sources that are } \\
\text { different by nature }\end{array}$ & $\begin{array}{l}\text { Bergquist and Söderholm, (2014) } \\
\text { Campos, 2009; Arnaiz et al., (2009), } \\
\text { Levrat et al., (2008), Murthy et al., } \\
\text { (2015), Aboelmaged, (2015), Muller } \\
\text { et al., (2008), Kour et al., (2014), Iung } \\
\text { et al., (2009), Aljumaili et al., (2015) } \\
\text { Wandt et al., (2012), Arnaiz et al., } \\
\text { (2009), Labib (2004), Wan et. al., } \\
\text { (2016), March and Scudder, (2017), } \\
\text { Bousdekis et. al., (2017) }\end{array}$ \\
\hline
\end{tabular}

\begin{tabular}{|c|c|c|}
\hline $\begin{array}{l}\text { Data Exchange and } \\
\text { Interoperability }\end{array}$ & $\begin{array}{l}\text { Sharing data and interconnecting all involved } \\
\text { systems in E-Maintenance }\end{array}$ & $\begin{array}{l}\text { Karim et al., (2009), Lim and Klobas, } \\
\text { (2000), Aljumaili et al., (2015), } \\
\text { Arnaiz et al., (2009), Campos (2014), } \\
\text { Karim et al., (2009), Campos (2014), } \\
\text { Wang and Xu (2013), Siegel (1998) }\end{array}$ \\
\hline Data Conversion & $\begin{array}{l}\text { Standardizing and unifying the data formats } \\
\text { which are being used and shared by all parties in } \\
\text { an E-Maintenance system }\end{array}$ & $\begin{array}{l}\text { (Tsang, 2002), Koç et al., (2003), } \\
\text { Bangemann et al., (2003), Moor and } \\
\text { Starr, (2006), Karim and Söderholm, } \\
\text { (2009), Jordan and Ellen, (2009), } \\
\text { Jantunen et al., (2010), Han and } \\
\text { Young, (2006), Koç et al., (2003), Lee } \\
\text { et al., (2006). }\end{array}$ \\
\hline
\end{tabular}

Each of these challenges are discussed further in the following sections.

\subsection{Data Acquisition}

Data Acquisition is the process of gathering relevant data and managing its content effectively (Wandt et al., 2012), and also the first step in E-Maintenance data management. Choosing the most appropriate data collection methods plays a deciding role in E-Maintenance data management due to related costs (Murthy et al., 2015), and due to risks of inadequate or wrong data failing the entire maintenance system (Jardine et al., 2006). Table 2 shows various types of data which are collected in E-Maintenance.

As a consequence of the importance of data for E-maintenance, a systematic approach to data acquisition is necessary (Jardine et al., 2006) to gather products' and assets' data in all lifecycle stages and to distribute data to stakeholders in order to enhance systems' effectiveness (Murthy et al., 2015). 
Furthermore, the collected data should be relevant and sufficient, to enable extracting desired information to support the decision making process (Aljumaili et al., 2015; Tretten and Karim, 2014). Collecting small or limited samples of data leads to poor modeling of maintenance system and consequently making poor maintenance decisions (Kobbacy et al. 2008). Furthermore, scarcity of timely and fact-based maintenance data, representing effectiveness of procurement, engineering and manufacturing, negatively impacts management of plants (Mobley et al. 2008). 
Table 2. Different types of data collected in E-Maintenance

\begin{tabular}{|c|c|c|c|}
\hline Data Type & Examples & Description & Contributors \\
\hline \multirow[t]{9}{*}{$\begin{array}{l}\text { Maintenance } \\
\text { Event Data }\end{array}$} & Technical data & $\begin{array}{l}\text { Electrical and mechanical data, manufacturer and equipment specification details, and the } \\
\text { guarantee period which is necessary for external maintenance engineers and workers }\end{array}$ & \multirow{9}{*}{$\begin{array}{c}\text { Kelley (1997), } \\
\text { Kelley (2006a), } \\
\text { Kelley (2006b), } \\
\text { Kelley (2006c), } \\
\text { Tsang et al., (2006), } \\
\text { Muller et al., (2008), } \\
\text { Mobley et al. (2008) } \\
\text { Tretten and Karim } \\
\text { (2014), } \\
\text { Wan et al., (2016), } \\
\text { Lee and Pan (2017), } \\
\text { Bousdekis et al., (2017) }\end{array}$} \\
\hline & Technical Drawings & $\begin{array}{l}\text { Includes both manufacturer and user drawings that are gathered by engineering department } \\
\text { and necessary to be updated. }\end{array}$ & \\
\hline & Maintenance Manual & $\begin{array}{l}\text { Instructions on how to maintain the failed item, or equipment, which like technical drawings } \\
\text { require updating. }\end{array}$ & \\
\hline & & A list of all spare parts stored in warehouse for each unit, accompanied with manufacturers' & \\
\hline & Spares Part Lists & Bill of Material (BOM), same or similar parts. & \\
\hline & Equipment Life Plan & A calendar-like plan that shows the inspection intervals for PM & \\
\hline & $\begin{array}{l}\text { Maintenance Job } \\
\text { Catalogues }\end{array}$ & $\begin{array}{l}\text { Shows the work order, work request, actions which should be carried out in inspections and } \\
\text { corrective maintenance actions, in case a degradation has been noticed and cost code for the } \\
\text { action implemented }\end{array}$ & \\
\hline & $\begin{array}{l}\text { Maintenance Control } \\
\text { Information }\end{array}$ & $\begin{array}{l}\text { Contains information on maintenance costs, plant availability and reliability control, and } \\
\text { includes plant history data such as failure's date, duration and cause as well as production or } \\
\text { quality losses }\end{array}$ & \\
\hline & $\begin{array}{l}\text { Operation and Safety } \\
\text { data }\end{array}$ & $\begin{array}{l}\text { Uncertainties and risks related to nature of maintenance actions, conditions under which the } \\
\text { maintenance action need to be done, sharing of safety rules }\end{array}$ & \\
\hline \multirow{4}{*}{$\begin{array}{l}\text { Condition } \\
\text { Monitoring Data }\end{array}$} & Value type & Condition monitoring data that are collected at a point of time and have single value & \multirow{4}{*}{$\begin{array}{c}\text { Jardine et. al. (2006), } \\
\text { Tsang et al., (2006), } \\
\text { Mobley, et al. 2008, } \\
\text { Hästbacka et al. (2016), } \\
\text { Karim et al., (2016), Lee } \\
\text { and Pan (2017) }\end{array}$} \\
\hline & Waveform type & $\begin{array}{l}\text { Condition monitoring data, collected at a point of time, based on time-series and have a trend } \\
\text { over time }\end{array}$ & \\
\hline & & Condition monitoring data, collected at a point of time and are multidimensional & \\
\hline & Multi-dimensional & & \\
\hline Product Data & $\begin{array}{l}\text { product structure } \\
\text { (BOM) }\end{array}$ & duct specifications, product faults and failure modes, etc. & \multirow{6}{*}{$\begin{array}{c}\text { Kelley (2006a), } \\
\text { Kelley (2006b), } \\
\text { Kelley (2006c), Murthy } \\
\text { et al., (2015) Wan et al., } \\
\text { (2016), Karim et al., } \\
\text { (2016) }\end{array}$} \\
\hline \multirow[t]{5}{*}{ Business Data } & e-Procurement data & $\begin{array}{l}\text { Spare parts' electronic ordering, Spare parts' order status, Spare parts' shipment notice, on- } \\
\text { line payment and invoicing }\end{array}$ & \\
\hline & Customer Relationship & Maintenance support and after-sale services, maintenance service ticketing & \\
\hline & $\begin{array}{l}\text { Management }(\mathrm{CRM}) \\
\text { data }\end{array}$ & & \\
\hline & $\begin{array}{l}\text { Supplier Relationship } \\
\text { Management (SRM) } \\
\text { data }\end{array}$ & $\begin{array}{l}\text { Sharing of maintenance data, joint training of maintenance personnel and mutual investment } \\
\text { on maintenance technology acquisition }\end{array}$ & \\
\hline & $\begin{array}{l}\text { Human Resource } \\
\text { Management data }\end{array}$ & Planning and assigning local and external maintenance personnel to tasks & \\
\hline
\end{tabular}


E-Maintenance data can be collected from either subjective or objective sources (Aljumaili et al., 2015). Subjective data deals with subjective judgement and assumptions made by human experts and decision makers while objective data is unbiased due to be free from human hypotheses and is created via computer models and sensors (Aljumaili et al., 2015). Regardless of the source, data needs to be consistent, highlighted by E-Maintenance systems requiring large volumes of data form various sources that can be geographically dispersed (Campos, 2009; Murthy et al., 2015).

\subsection{Rapid Flow of Information}

E-Maintenance is an intelligent and knowledge-based maintenance system that involves a rapid flow of information among diverse groups of actors who utilize the shared insights from remote monitoring of assets to decide about equipment's diagnosis, degradation and future Remaining Useful Life (RUL) in a collaborative fashion (Iung, 2003).

The integration of different business processes in E-Maintenance systems, removes isolated islands of information and creates a bi-directional flow of information and knowledge which improves the quality of decision making (Moore and Starr, 2006). Moreover, in contrast to conventional maintenance approaches where information flow is uncooperative, in E-Maintenance information exchange has approximated working relations (Candell et al., 2009).

Although merging maintenance-related business processes supports better information flows at all levels (Campos, 2009; Hausladen and Bachheim, 2004) and results in lower system downtime (Lee et al., 2006), it has also some negative sides. In some maintenance systems, lack of continuous and seamless flow of information hinders instant understanding and usefulness of collected data (Kobbacy et al. 2008). In more sophisticated systems, information flow is faster (Candell et al., 2009), while in E-Maintenance each involved system should control information flow (Zhang et al., 2003). Each actor involved in EMaintenance must be able to follow the rapid information flow (Muller et al., 2008), therefore, the overall information flow should be constructed systematically to allow identifying how the overall system functions (Lee, 2003).

\subsection{Data Quality}

Data quality has been defined in the following manner: "the level of quality of data represents the degree to which data meets the expectations of data consumers, based on their intended use of the data" (Sebastian-Coleman, 2012). Data quality is the process of assuring that data follows certain specifications and is fit for different organizational purposes (Jordan and Ellen, 2009). Data quality has different dimensions of data: accuracy, consistency, integrity and timeliness (Aljumaili et al., 2015). Practically, data quality involves "cleaning" data from errors manually or by using computerized graphical tools to have high quality data from data collection to further data modeling, analysis, fusion and integration processes (Jardine et al., 2006). Data cleaning is an ongoing process which should be carried out with limited manual and programming tasks, not only in data collection phase, but also as the data is being merged from various sources.

Collecting high-quality data significantly affects the success of an enterprise (Sebastian-Coleman, 2012). Without reliable data, maintenance organization cannot evaluate the advantages of its maintenance system (Mobley et al. 2008). Additionally, in E-Maintenance high quality data directly influence final decisions (Tretten and Karim, 2014), and regardless of how sophisticated the E-Maintenance technology is, collecting and feeding poor quality 
data to the system results in low quality decisions, even referred to as "garbage in garbage out" (Jantunen et al., 2010; Jardine et al., 2006).

There are different reasons why data-quality problems occur in an E-Maintenance system. Maintenance event data which are collected manually from subjective sources contribute to 80 per cent of data-qualityrelated problems (Jardine et al., 2006), On the other hand, in condition monitoring, poor quality data are caused by faulty sensors which may collect "noisy" data (Jardine et al., 2006). Such data are filled with meaningless or truncated data that does not contain enough details (Lin et al., 2006). This low quality data gathered in diagnosis stage, will be then used in modeling, resulting in adverse effect on prognosis stage (Bergquist and Söderholm 2014).

Assuring high-quality and promptness of data in E-Maintenance systems is highlighted due to versatile sources and sharing the data with different actors (Tsang et al. 2006). In fact, it can be better not to share any data if its quality is not controlled (Jordan and Ellen, 2009). In order to improve data quality, a clear and unified definition of data quality is necessary, including principles for developing processes of assuring data quality (Jordan and Ellen, 2009). It is essential that each organization involved in EMaintenance can make enterprise-wide decisions for generating higher quality data (Sebastian-Coleman, 2012).

\subsection{Voluminous and Heterogeneous Data}

This challenge refers to large volumes of data that are generated, and acquired from heterogeneous sources. E-Maintenance data are collected from RFID tags, sensors, PDAs and maintenance operators in different stages of asset's lifecycle. Real-time data from heterogeneous environments, need to be aggregated to E-Maintenance information system (Aboelmaged, 2015; Muller et al., 2008).

Although the advancements of ICTs have provided the foundation for collecting and processing massive data from diverse origins (Iung et al., 2009), some challenges remain. Vast data from numerous sources, threatens the data quality and makes obtaining information and interoperability between systems problematic (Aljumaili et al., 2015; Wandt et al., 2012). Although merging information from multiple sources and collecting large volumes of data may support maintenance (Arnaiz et al., 2009; Labib 2004), it impedes fault diagnosis and knowledge acquisition from uncleaned data (Kour et al., 2014). In other words, acquiring large amount of data and consequently huge data analysis effort may outweigh the advantages of data collection (Mobley et al. 2008).

\subsection{Data Exchange and Interoperability}

Information should flow smoothly among all stakeholders, but collecting heterogeneous data impedes interconnectivity and integration (Karim et al., 2009). Interoperability which is one of the most significant characteristics of an enterprise, is defined as the system's ability to share information or swap services between two or more systems and then co-operate based on the shared information or exchanged services.

Interoperability, considers data contexts within data systems and creates a common platform for data exchange (Aljumaili et al., 2015), helps further different software systems to work together regardless of their location, operating system or programming language (Siegel, 1998). In order to assure interoperability, constituent systems should interpret data accurately and in a right context (Lim and Klobas, 2000). Standards, data exchange models and communication protocols further stabilize the data 
delivery (Aljumaili et al., 2015). They develop interoperability among multiple systems, including maintenance and manufacturing (Ray and Jones, 2006).

The tools that assure interoperability in E-Maintenance systems, include Web technologies (Arnaiz et al., 2009; Campos, 2014; Karim et al., 2009), Cloud Computing (Campos, 2014; Wang and Xu, 2013), and such. Web technologies provide a platform to share and reuse information among different applications and parties on the net via shared structures such as Semantic frameworks. Although, Semantic frameworks let involved actors manage data over the net (Campos 2014), one of the challenges in E-Maintenance is to fit the semantic framework for maintenance functions in a way that exchanged information over the internet can be defined for different E-Maintenance environments (Arnaiz et al. 2009). Cloud computing can also establish a basis for E-Maintenance actors to access, not only shared information, but also shared network, services and computing resources in real-time (Wang and Xu 2013).

\subsubsection{Interoperability and Data Exchange Standards}

Regardless of web-technologies and cloud-computing which are general solutions for data exchange, there are tools and standards created, for assuring interoperability in E-maintenance systems. International Organization for Standardization (ISO) has defined ISO 13374:2012 on Condition monitoring and diagnostics of machines - Data processing, communication and presentation. ISO-13374, defines six blocks of functionality in a condition monitoring system, as well as the general inputs and outputs of those six blocks. These six blocks include Advisory Generation, Prognostics Assessment, Health Assessment, State Detection, Data Manipulation and Data Acquisition (Prajapati et al. 2012). Table 3 lists some of condition monitoring standards, developed by ISO.

Table 3. Condition monitoring and diagnostics of machines - Data processing, communication and presentation standards, developed by ISO (ISO 2018)

\begin{tabular}{|c|c|c|}
\hline Standard & Subject & Scope \\
\hline ISO 13374-1 & $\begin{array}{l}\text { Condition monitoring and diagnostics of } \\
\text { machines - Data processing, communication } \\
\text { and presentation - Part } 1 \text { : General guidelines }\end{array}$ & $\begin{array}{l}\text { Provides general guidelines for software } \\
\text { specifications related to data processing, } \\
\text { communication, and presentation of machine } \\
\text { condition monitoring and diagnostic } \\
\text { information }\end{array}$ \\
\hline ISO 13374-2 & $\begin{array}{l}\text { Condition monitoring and diagnostics of } \\
\text { machines -- Data processing, communication } \\
\text { and presentation - Part 2: Data processing }\end{array}$ & $\begin{array}{l}\text { Explains reference information model and } \\
\text { reference processing model, to which open } \\
\text { condition monitoring and diagnostics (CM\&D) } \\
\text { architectures need to adapt }\end{array}$ \\
\hline ISO 13374-3 & $\begin{array}{l}\text { Condition monitoring and diagnostics of } \\
\text { machines -- Data processing, communication } \\
\text { and presentation - Part 3: Communication }\end{array}$ & $\begin{array}{l}\text { Details data communication requirements for } \\
\text { an open condition monitoring and diagnostics } \\
\text { (CM\&D) reference information architecture } \\
\text { and reference processing architecture }\end{array}$ \\
\hline ISO 13374-4 & $\begin{array}{l}\text { Condition monitoring and diagnostics of } \\
\text { machine systems -- Data processing, } \\
\text { communication and presentation - Part 4: } \\
\text { Presentation }\end{array}$ & $\begin{array}{l}\text { Specifies the requirements, needed for } \\
\text { presentation of information for technical } \\
\text { analysis and decision support in condition } \\
\text { monitoring and diagnostics open architecture. }\end{array}$ \\
\hline
\end{tabular}


Another major contributor to maintenance data agreements is Machinery Information Management Open System Alliance (MIMOSA). MIMOSA is a non-profit industry association, dedicated to the development and adoption of open information standards for operations and maintenance applications in manufacturing, fleet, and facility environments (Campos, 2014). Table 4 shows the most common standards, developed by MIMOSA.

\subsection{Data Conversion}

One of the major threats in E-Maintenance data management, is information buried in E-Maintenance big data, originally generated through the system's lifecycle and ending up hidden in versatile places and formats (Tsang, 2002). This big raw data is usable only if it is converted into appropriate formats (Koç et al., 2003). Linkage of different systems exacerbates the situation as involved actors need to share data in diverse locations, each using different data-formats and generating huge amounts of data (Bangemann et al., 2003). This problem makes data incompatible and reduces the data quality, impeding the business processes (Bose 2006).

The solution to aforementioned problem, is standardizing the format in which data is archived, processed and then exchanged among distinctive systems (Karim and Söderholm, 2006). In fact, data should be delivered in an identical format to have a unified understanding of same data among different business systems (Jordan and Ellen, 2009).

Having identical data formats in maintenance, is needed in all stages of product lifecycle (Jantunen et al., 2010). Therefore data conversion is a data pre-processing task and plays a vital role in optimizing maintenance systems (Kobbacy et al., 1995). Hence, E-Maintenance system should have a scalable and reconfigurable platform, capable of converting data to information and information to knowledge, supporting harmonization with other processes (Han and Young, 2006; Koç et al., 2003; Lee et al., 2006).

\section{Current State Analysis}

E-maintenance data management process in the analyzed company has five different stages, namely: Data Collection, Data Transfer, Data Fusion, Data Analysis, Visualization or Information Sharing that are in line with the Aljumaili et al. (2015) and Jardine et al. (2006). Figure 2 shows this process. The process starts by acquiring versatile types of data from heterogeneous sources over different organizational levels. The purpose of data collection is defined collaboratively by customers and the studied company. This data collection also forms the basis for internal traceability of the products. An interviewee described the situation as: “..., equipping assets and their components with e-technologies enables tracing products from top level of the asset (as a whole product), down to different levels of Bill of Material". Condition monitoring data are collected via sensors in real-time or entered manually through mobile devices such as smart phones or PC tablets by professional service technicians.

Although, the company has prepared standards for data collection based on different products, data collection can be affected also by customers' will and the industry they are active in. This was commented as: "..., it could be also that there are other ways to reach safe service level with the customers like military and nuclear but in normal manufacturing type of approach customer does not have any problem with letting data go out of their premises." 
Table 4. Most common data exchange and interoperability standards, developed by MIMOSA

\begin{tabular}{|c|c|c|}
\hline Name of Standard & Scope & Advantages \\
\hline $\begin{array}{l}\text { Common Collaborative Object Model } \\
\text { (CCOM) }\end{array}$ & $\begin{array}{l}\text { An information model for the exchange of asset information } \\
\text { and to facilitate standards-based interoperability between } \\
\text { systems (MIMOSA 2018) }\end{array}$ & $\begin{array}{l}\text { 1. Effectively representing data for the } \\
\text { purpose of data exchange (MIMOSA } \\
\text { 2018) } \\
\text { 2. Providing a cleaner and more flexible } \\
\text { model for Enterprise Application } \\
\text { Integration (MIMOSA 2018) }\end{array}$ \\
\hline $\begin{array}{l}\text { Common Relational Information Schema } \\
\text { (CRIS) }\end{array}$ & $\begin{array}{l}\text { A relational database model for different data types which } \\
\text { needed to be processed in condition-based maintenance (CBM) } \\
\text { applications (Campos 2009) }\end{array}$ & $\begin{array}{l}\text { 1. Enabling information and data exchange } \\
\text { between plant and machinery maintenance } \\
\text { information systems (Arnaiz et al. 2009) } \\
\text { 2. Providing an open exchange standard in } \\
\text { key asset management areas (Campos } \\
\text { 2009) }\end{array}$ \\
\hline $\begin{array}{l}\text { Open System Architecture for Enterprise } \\
\text { Application Integration (OSA-EAI) }\end{array}$ & $\begin{array}{l}\text { A layered architecture to provide: } \\
\text { - An information exchange standard for asset registry, } \\
\text { diagnostic and prognostic assessment, maintenance and } \\
\text { reliability information between enterprise systems } \\
\text { (Holmberg et al.. 2010) } \\
\text { - Solves integration of different applications (Holmberg et } \\
\text { al.. 2010) }\end{array}$ & $\begin{array}{l}\text { 1. Facilitating the integration of asset } \\
\text { management information (MIMOSA } \\
\text { 2018) } \\
\text { 2. Provides flexibility with price of } \\
\text { performance, in case all suppliers follow } \\
\text { same standards (Holmberg et al.. 2010) }\end{array}$ \\
\hline $\begin{array}{l}\text { Open System Architecture for Condition- } \\
\text { Based Maintenance (OSA-CBM) }\end{array}$ & $\begin{array}{l}\text { A standard architecture for information flow in CBM systems } \\
\text { based on six blocks of functionality in condition monitoring } \\
\text { systems (Prajapati et al. 2012), defined in ISO-13374 }\end{array}$ & $\begin{array}{l}\text { Enabling interoperability of CBM } \\
\text { components (Holmberg et al. 2010) } \\
\text { 2. Enabling software engineers to use a } \\
\text { standard architecture for information flow } \\
\text { in CBM systems (Holmberg et al. 2010) } \\
\text { 3. Enabling all vendors to use same input and } \\
\text { output interfaces (MIMOSA 2018) } \\
\text { 4. Enabling Vendors to work on separate } \\
\text { modules (MIMOSA 2018) }\end{array}$ \\
\hline
\end{tabular}


The analyzed company acquires data both from subjective and objective sources: "For the real-time (monitoring) it is all gathered by the sensors and then we go to more traditional type of maintenance, it is done mostly by human." The subjective and objective maintenance data are both treated as important and in some cases they complement each other. The use of humans was commented as: "..., so it kind of means that we sometimes do not trust the data we gather from sensors and we send a technician. If sensors show that there was an overload or over-temperature, a technician will be sent to follow the case".

In plant or organizational level, Manufacturing Data and Maintenance Service Data are collected from Production Planning System and maintenance event data, respectively. Comparing maintenance event data, such as maintenance logs and histories with real-time condition monitoring data results to estimation of Remaining Useful Life (RUL) of the asset. In Supply chain level, the latest data on spare parts inventory can be derived from Supplier Relationship Management System (SRM).

In Business level, there are three different types of data collected, namely Customer Data, Financial Data and Workforce Data. Customer Data are collected from CRM tool. An interviewee described the situation as: “..., when an equipment's serial number is entered to the system, information such as customer's details, equipment's location, its usage and maintenance history, and its current condition can all be traced. Financial Data such as maintenance cost controlling are acquired from Financial Data Management systems. Workforce Data which helps in planning and assigning maintenance engineers and technicians to maintenance actions are also captured from Human Resource Management System.

The collected data are then sent (Data Transfer) to a remote data warehouse, where they are centralized together (Data Fusion).

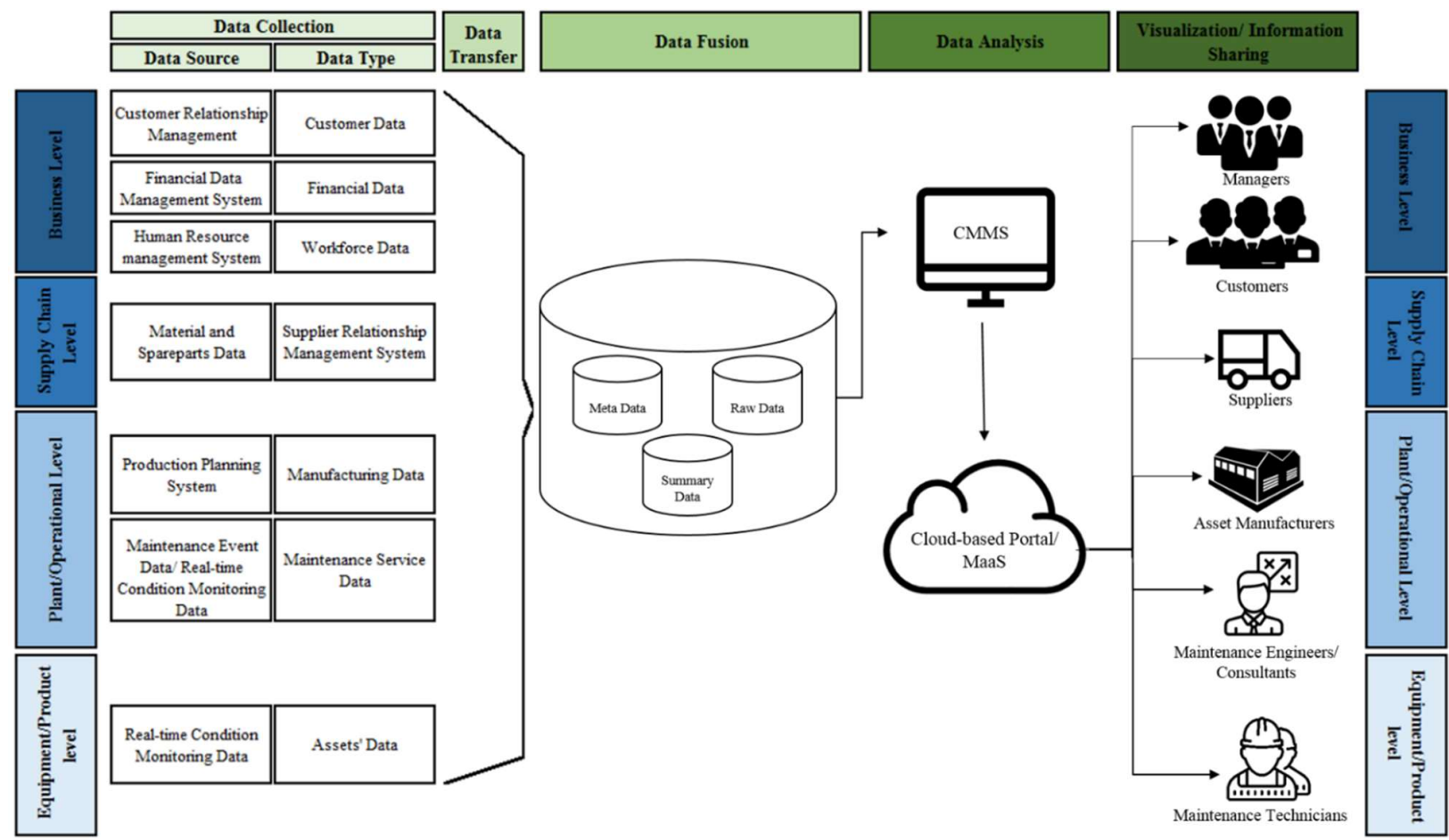

Figure 2. Data Management Process in E-Maintenance System of studied company 
Aligned with Mobley et al. (2008), in Data Analysis stage, a Computerized Maintenance Management System (CMMS) parses the data. CMMS is a sophisticated standalone system within large maintenance organization or a fleet of assets which integrates maintenance-related data from various departments across the enterprise, aiming at enhancing maintenance plans. Analyzed data, including anomalies, trends, inter-related variables and patterns are then presented on a portal in a form of graphs, charts and tables for a single asset or whole fleet over any chosen time interval which provides the necessary data for scheduling both preventive and corrective maintenance tasks.

In Information sharing stage, the portal is a cloud-based platform which gives different stakeholders from different organizational levels a crystal clear overview of maintenance-related information. In Business Level, information can be shared with higher managers and customers (in case, the company is acting as a maintenance service provider). In Supply Chain level, information can be shared with spare parts and material suppliers to ensure Just-in-Time delivery of spare parts. As also stated by (Holmberg et al. 2010), this real-time information sharing thus establishes an open and virtual collaboration among different departments, facilitates decision making, and enhances the maintenance efficiency.

In Plant or Operational Level, The analyzed company, or the asset manufacturer can also use this data for Research and Development (R\&D) and product development purposes. The use of the data was described by an interviewee as follows: " $R \& D$ and product developments, so when we are having knowledge about our products that is one of the things and we always design products of high quality and safety, so these are also some of the things we are monitoring ourselves." Therefore, they can enhance products' quality and safety, and gain understanding whether the failed component has been produced in-house or supplied by a specific supplier. ".

After data has been shared with involved stakeholders, maintenance decisions are made. CMMS documents maintenance decisions and schedules maintenance actions. In Equipment or Product Level, maintenance technicians equipped with mobile devices can receive new maintenance schedules or maintenance manuals right on their mobile devices or Personal Digital Assistants (PDAs). After maintenance actions have been performed, technicians will update the maintenance history and document the maintenance action into the CMMS.

Figure 3 illustrates the analyzed E-Maintenance system, based on Process Activity Mapping. Process Activity Mapping is a preliminary tool related to lean methodology, practical for studying the process flow (Hines and Rich, 1997), supporting system engineers to understand the current processes, and to propose an improved future state 


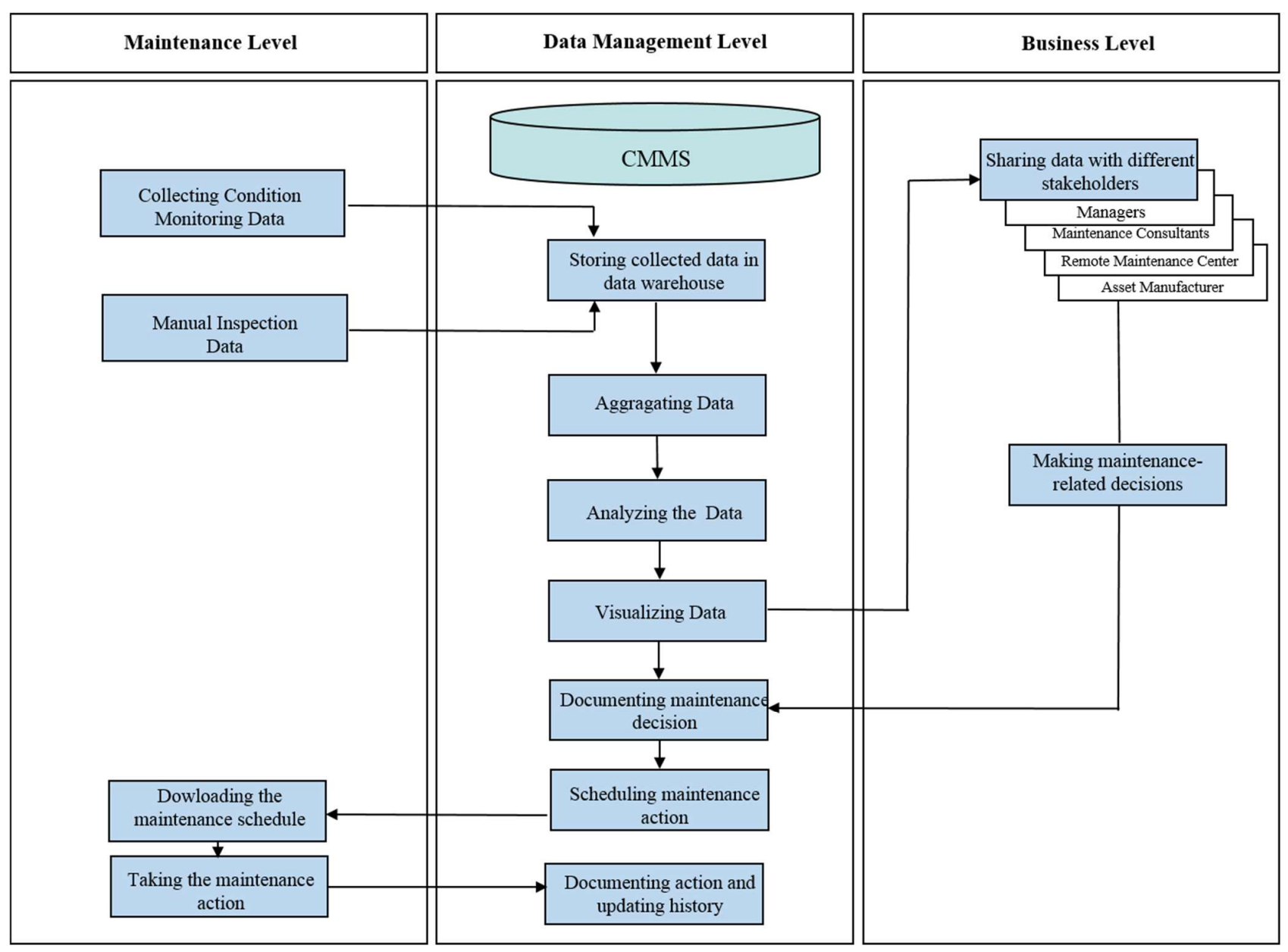

Figure 3. Analyzed E-Maintenance system

\section{Discussion}

Analyzing the current state of studied company's E-Maintenance validates the findings of literature review on data management challenges in E-Maintenance systems. The criticality of customers, number of stakeholders involved, type, size and complexity of services such as different geographical locations, are among the relevant challenges. Looking at the current state of E-Maintenance system, it has been observed that there are no actions on checking the collected data, whether or not it meets involved stakeholders' expectations. Therefore, in order to overcome data management challenges, following solutions are proposed (Table 5) and future state is distilled (Figure 4). This future state has been presented and discussed with studied company and feedback has been collected. 
Table 5. Proposed solutions for overcoming data management challenges in E-Maintenance

\begin{tabular}{|c|c|c|}
\hline Challenges & Associated Problem & Proposed Solution \\
\hline Data Acquisition & $\begin{array}{l}\text { Collecting data from versatile resources that } \\
\text { may be irrelevant and inadequate for } \\
\text { maintenance decision making }\end{array}$ & $\begin{array}{l}\text { Planning the data collection } \\
\text { collaboratively with all involved } \\
\text { stakeholders and defining the data } \\
\text { collection KPIs }\end{array}$ \\
\hline $\begin{array}{l}\text { Voluminous and } \\
\text { Heterogeneous Data/ }\end{array}$ & $\begin{array}{l}\text { Large volumes of data are generated, and } \\
\text { acquired from heterogeneous sources }\end{array}$ & $\begin{array}{l}\text { Acquiring the data according to } \\
\text { defined data collection KPIs reduces }\end{array}$ \\
\hline $\begin{array}{l}\text { Rapid Information } \\
\text { Flow }\end{array}$ & $\begin{array}{l}\text { Lack of systematic information flow, causing } \\
\text { fast flow of information in all directions } \\
\text { among stakeholders }\end{array}$ & $\begin{array}{l}\text { the amount of collected data and as a } \\
\text { result leads to a smooth information } \\
\text { flow }\end{array}$ \\
\hline Data Quality & $\begin{array}{l}\text { Collecting noisy, truncated and meaningless } \\
\text { data from objective and subjective sources }\end{array}$ & $\begin{array}{l}\text { Automating the data collection } \\
\text { through sensors, and prompt } \\
\text { cleaning of data }\end{array}$ \\
\hline $\begin{array}{l}\text { Data Exchange and } \\
\text { Interoperability }\end{array}$ & $\begin{array}{l}\text { Lack of standards, data exchange models and } \\
\text { communication protocols throughout the E- } \\
\text { Maintenance system }\end{array}$ & $\begin{array}{l}\text { Establishing compatible information } \\
\text { systems inside and outside of } \\
\text { stakeholders' organizations }\end{array}$ \\
\hline Data Conversion & $\begin{array}{l}\text { Converting raw E-Maintenance data into } \\
\text { appropriate formats which can be utilized by } \\
\text { all parties }\end{array}$ & $\begin{array}{l}\text { Standardizing data formats within E- } \\
\text { Maintenance system }\end{array}$ \\
\hline
\end{tabular}




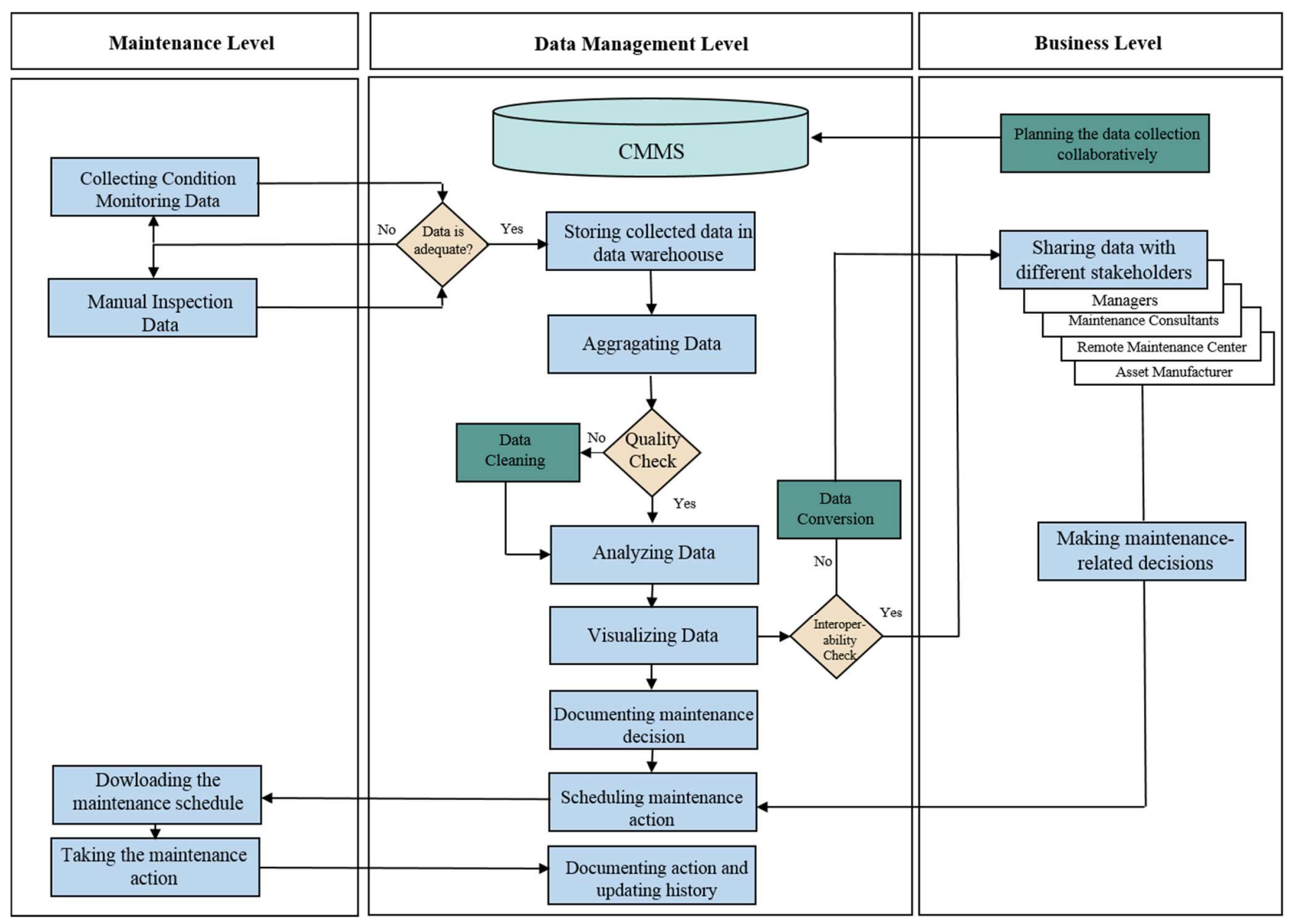

Figure 4. Proposed Process Activity Mapping for Future E-Maintenance system

Before data acquisition starts, the future E-maintenance requires that all involved stakeholders, managers, maintenance consultants and engineers, spare parts suppliers, assets manufacturer, and such, collaboratively define data acquisition standards and KPIs. Data acquisition is expensive. If there are no policies for collecting data or if there is no observance whether the collected data is relevant or sufficient for the aims of data collection, the quality of final decisions will be poor which lead to poor-quality actions. Therefore, In line with Mobley et al.(2008), it is of high importance that E-Maintenance system includes data collection and evaluation plans where all involved parties define data acquisition standards collaboratively and feed those standards to CMMS, which is the heart of an E-Maintenance system.

These data collection KPIs include what type of data form what source to collect and for what purpose such data should be collected. Therefore, data volume and number of sources that the data need to be collected from, will be minimized and right data with higher levels of accuracy will be collected. Data collection KPIs can vary based on different customers' business strategies or the industry that customer is active in. For instance, different maintenance strategies such as "producing high quality products" or "reducing the downtime", or different industries such as automotive or food industry, requires different maintenance approaches and therefore, different data need to be collected. 
These data collection KPIs and standards also mean transparent definition of what data quality means for all involved parties, inside and outside of their organizations. Therefore, all involved stakeholders should have a common and enterprise-wide understanding towards data quality. Moreover, all stakeholders should commit regarding collecting high-quality data, so that high-quality data are collected right from the relevant sources. Since sensors and other e-technologies, used for data acquisition are less error-prone compared to human, data collection should be more automated.

Once data is collected from subjective and objective sources, E-Maintenance service provider or the party in charge of data collection, compares acquired data with pre-defined data collection KPIs. If collected data from different sources fit data acquisition standards, then it can be assured that the collected data is adequate and relevant for the purpose of data collection. If not, then more data or maybe even data from other or new sources need to be collected. This checkpoint smoothens the information flow and prevents waste actions such as data pre-processing

Collected condition monitoring data can be considered as a new business and a source of revenue. Companies can purely offer data collection and data analysis as a service to assets owners and other third parties without offering associated maintenance actions. As a result, data collection should start by considering data both from IT and business perspective.

Data is further aggregated from different sources and systems (earlier Figure 2), but before starting the data analysis, the quality of data needs to be approved. Data quality checks whether or not, collected data is "Fit-for-Use" Should the data be messy or noisy, data cleaning actions should be carried out as soon as possible and collaboratively with other stakeholders. In this way, all involved parties are aware of what data has been eliminated or what actions have been done for cleaning noisy and dirty data.

If the quality of acquired data has met the data collection KPIs and fits the aim of data collection, data processing takes place, aiming at converting the data into information and preparing for maintenance decision-making. After data has been analyzed, the obtained information is visualized. But prior to sharing information to right stakeholders and other decision-makers, data unification and interoperability should be checked. Data Unification focuses on solving interoperability, data conversion challenges and standardizing data formats within an E-Maintenance system. Since data is being shared among different organizations, the role and the type of information system may vary from each party to others. Therefore Data Unification requires commitment and effort from all E-Maintenance stakeholders in order to establish compatible information systems not only with other involving parties but also within their own organizations by using web-technologies and cloud-computing

Cloud computing and Web technologies, facilitate not only sharing data and information, but also infrastructures like networks, servers and services by applying same maintenance-related tools. In case the data is in a wrong format, the data format should be unified before sharing with other actors. Data Unification focuses on solving interoperability and data conversion challenges and standardize data formats like Extensive Markup Language (XML) within E-Maintenance system, so that all stakeholders can easily share data and information, interpret the data accurately and in a right context, and as a result have a common understanding over the exchanged data. Therefore, when all stakeholders make their information systems consistent and adaptable, use enabling technologies as well as standard and identical data formats, they can share data easily and seamlessly to right actors, apart from their locations and make right decisions. 
After data has been shared with right parties, the maintenance-related decisions (e.g. ordering spare parts, fixing the asset, etc.) are made. These decisions are then sent and documented in CMMS as a Decision Support System (DSS). CMMS schedules maintenance actions, while considering several factors such as criticality of customers and availability of workforce or spare parts. Maintenance technicians on customers' site can download the maintenance schedules via their mobile devices. Finally, after technicians have performed the maintenance actions, they document maintenance actions on CMMS and update asset's maintenance history via their mobile devices.

\section{Scientific implications}

The scientific implications of this study include providing new contribution to E-Maintenance and the different perspectives covered by the previous literature (Aboelmaged 2015, Iung et al., 2009, Muller et al., 2008, Levrat et al., 2008, Bangemann et al., 2006) by highlighting the deficiencies of the discussion surrounding the perspectives of data management in E-Maintenance. On the contrary of (Aboelmaged 2015, Campos 2014, Jantunen et al., 2010) who have studied E-Maintenance from technological, economical or managerial views, this study identifies the most common data management challenges in E-Maintenance systems. Unlike (Campos et. al., 2016, Murthy et al., 2015, Aljumaili et al., 2015, Tretten and Karim, 2014, Candell et al., 2009) who discuss specific data management issues in the context of EMaintenance, this research has studied all common data management challenges and listed different types of data which need to be acquired in E-Maintenance systems. Additionally, In line with Wan et al., (2017), the role of close collaboration among all involved stakeholders in E-Maintenance has been highlighted in this study.

\section{Managerial implications}

Managerial implications include emphasizing how understanding the E-Maintenance related challenges helps maintenance managers and other involved stakeholders in E-Maintenance systems to better solve the challenges. These findings, based on the practices of an E-Maintenance industry leader, and validating the data management challenges presented in the literature, provide managers confidence to develop the activities in their companies. Thanks to Process Activity Mapping, the proposed future state of E-Maintenance may provide food for thought for practitioners to understand the big picture over EMaintenance and to develop their practices. Overall, the findings can be utilized by maintenance managers as a practical way of overcoming data management challenges in E-Maintenance.

\section{Conclusion}

Data management challenges in E-Maintenance have been studied with narrow focus to data and appear as one of the less-studied topics in the literature. Hence, this paper further analyzes data management challenges in E-Maintenance systems and propose a conceptual approach to address identified challenges in practice. The study is realized as a combination of a literature review and by the means of analyzing the practices on an industry leader. The identified data management challenges that relate to EMaintenance systems and their associated proposed solutions are summarized.

Analyzing the practices of the industry leader allowed mapping the current state of E-Maintenance systems. The study revealed that although the analyzed company is an industry-leader in offering 
maintenance services, E-Maintenance is not fully implemented in practice and more remote maintenance than the use of an actual E-Maintenance system may take place. Underlying data management challenges were identified and an improved state was proposed.

The study provides understanding over E-Maintenance by bringing together relevant aspects that are typically addressed in a more dispersed manner. However, since the study is based on analyzing the practices of a single company and the supporting documentation, the generalizability of the results may be limited, and the proposed approach might have limitations in suitability for use in other companies or industries. Also, the study provided a general understanding over data management challenges in EMaintenance which was based on qualitative methods, including interviews and reviewing company confidential materials, potentially posing some further limitations. Therefore, in order to strengthen the findings, future research topics can focus on each of mentioned data management challenges more deeply. Future research include further validating the presented model by analyzing its applicability in other companies and industries. Considering how to balance internal and external data usage, and the use of quantitative methods, such as data mining for analyzing maintenance data from different perspectives and converting data into knowledge are also encouraged.

\section{References}

Aboelmaged, M. G. S., 2015. E-maintenance research: a multifaceted perspective, Journal of Manufacturing Technology Management, 26(5), 606 - 631.

Aljumaili, M., Wandt, K., Karim, R., Tretten, P., 2015. eMaintenance ontologies for data quality support, Journal of Quality in Maintenance Engineering, 21(3), 358 - 374.

Arnaiz, A., Gilabert, E., Jantunen, E., Adgar, A., 2009. Ubiquitous computing for dynamic conditionbased maintenance, Journal of Quality in Maintenance Engineering 15(2), 151 - 166.

Bangemann, T., Rebeuf, X., Reboul, D., Schulze, A., Syzmanski, J., Thomesse, J., Thron, M., Zerhouni, N., 2006. PROTEUS - creating distributed maintenance systems through an integration platform, Computers in Industry 57, 539-551.

Bergquist, B., Söderholm, P., 2015. Data Analysis for Condition-based Railway Infrastructure Maintenance, Quality and Reliability Engineering International 31, 773-781.

Bose, R., 2006. Understanding management data systems for enterprise performance management, Industrial Management \& Data Systems, 106(1), 43 - 59.

Boudekis, A., Papageorgiou, N., Magoutas, B., Apostolou, D., Mentzas, G., 2017, A proactive eventdriven decision model for joint equipment predictive maintenance and spare parts inventory optimization, The 5th International Conference on Through-life Engineering Services (TESConf 2016), $1^{\text {st }}$ to $2^{\text {nd }}$ November 2016, Canfield, UK.

Campos, J., 2009. Development in the application of ICT in condition monitoring and maintenance, Computers in Industry 60, 1-20. 
Campos, J., 2014. Current and prospective information and communication technologies for emaintenance applications, Journal of Quality in Maintenance Engineering, 20(3), 233-248.

Campos, J., Sharma, P., Jantunen, E., Baglee, D., Fumagalli, L., 2016. The challenges of cybersecurity frameworks to protect data required for the development of advanced maintenance, Procedia CIRP 47, 222-227.

Candell, O., Karim, R., Söderholm, P., 2009. eMaintenance-Information logistics for maintenance support, Robotics and Computer-Integrated Manufacturing 25, 937-944.

Guba, E. G., Lincoln, Y. S., 1981. Effective Evaluation. San Francisco, CA: Jossey-Bass Publishers, ISBN: 9780875894935,423 pages.

Han, T., Yang, B.S., 2006. Development of an e-maintenance system integrating advanced techniques, Computers in Industry 57, 569-580.

Hästbacka, D., Jantunen, E., Karaila, M., Barna, L., 2016, Service-based Condition Monitoring for Cloud-enabled Maintenance Operations, IECON 2016 - 42nd Annual Conference of the IEEE Industrial Electronics Society, p. 5289-5295, 24 $4^{\text {th }}-27^{\text {th }}$ October 2016, Florence, Italy

Hausladen, I., Bechheim, C., 2004. E-maintenance platform as a basis for business process integration, Proceedings of INDIN04, 2nd IEEE International Conference on Industrial Informatics, Berlin, 24-26 June, 46-51.

Hines, P., Rich, N., 1997. The seven value stream mapping tools, International Journal of Operations and Production Management, 17 (1), 46-64, doi: 10.1108/01443579710157989

Holmberg K., Adgar A., Arnaiz A., Jantunen E., Mascolo J., Mekid S., 2010. E-maintenance, Springer, ISBN 978-1- 84996-205-6,

International Organization for Standardization (ISO), 2012. Condition monitoring and diagnostics of machines - Data processing, communication and presentation, available from: https://www.iso.org/standard/37611.html, accessed July 2018.

Iung, B., 2003. From remote maintenance toMAS-based e-maintenance of an industrial process, Journal of Intelligent Manufacturing 14, 59-82.

Iung, B., Levrat, E., Crespo-Marquez, A., Erbe, H., 2009. Conceptual framework for e-Maintenance: Illustration by e-Maintenance technologies and platforms, Annual Reviews in Control 33, 220229.

Jantunen, E., Emmanouilidis, C., Arnaiz, A., Gilabert, E., 2010. Economical and Technological prospects for e-Maintenance, International Journal of System Assurance Engineering Management, 1(3), 201-209

Jardine, A.K.S., Lin, D., Banjevic, D., 2006. A review on machinery diagnostics and prognostics implementing condition-based maintenance, Mechanical Systems and Signal Processing, 20(7), 1483-1510. 
Jordan, J., Ellen, C., 2009. Business need, data and business intelligence, Journal of Digital Asset Management 5, $10-20$.

Karim, R., Söderholm, P., 2009. Application of information and communication technology for maintenance support information services, Journal of Quality in Maintenance Engineering, 15(1), $78-91$.

Karim, R., Candell, O., Söderholm, P., 2009. E-maintenance and information logistics: aspects of content format, Journal of Quality in Maintenance Engineering, 15(3), 308 - 324.

Karim, R., Westerberg, J., Galar, D., Kumar, U., 2016. Maintenance Analytics - The New Know in Maintenance, IFAC-PapersOnLine 49-28, 214-219

Kelly, A., 1997. Maintenance Organizations \& Systems: Business-Centred Maintenance, ButterworthHeinemann, Oxford, ISBN: 978-0750636032, 320 pages

Kelley, A., 2006a. Maintenance Systems and Documentation, Oxford, UK: Butterworth-Heinemann, ISBN: 9780080462622,264 pages.

Kelley, A., 2006b. Strategic Maintenance Planning, Oxford, UK: Butterworth-Heinemann, ISBN: 9780080478999, 304 pages.

Kelley, A., 2006c. Managing Maintenance Resources, Oxford, UK: Butterworth-Heinemann, ISBN: 9780750669931, 292 pages.

Kobbacy, K.A.H., Proudlove, N.C., Harper, M.A., 1995. Towards an intelligent maintenance optimization system, Journal of the Operational Society 46, 831-853.

Kobbacy K., Murthy D., 2008. Complex System Maintenance Handbook, Springer Science \& Business Media, Springer Series in Reliability Engineering, ISBN 978-1-84800-010-0

Koç, M., Ni, J., Lee, J., Bandyopadhyay, P., 2003. Introduction of e-manufacturing. In: Proceedings of the 31st North American manufacturing research conference (NAMRC), Hamilton, Canada, 2003.

Kour, R.,Tretten, P., Karim, R., 2014. eMaintenance solution through online data analysis for railway maintenance decision-making, Journal of Quality in Maintenance Engineering, 20(3), 262- 275.

Labib, A.W., 2004. A decision analysis model for maintenance policy selection using a CMMS, Journal of Quality in Maintenance Engineering, 10(3), 191-202.

Lee, J., 2003. E-manufacturing: fundamental, tools, and transformation. Robotics and ComputerIntegrated Manufacturing, 19(6), 501-507.

Lee, J., Ni. J., Djurdjanovic, D., Qiu, H., Liao, H., 2006. Intelligent prognostics tools and emaintenance, Computers in Industry 57, 476-489.

Lee, D., Pan, R., 2017. Predictive maintenance of complex system with multi-level reliability structure, International Journal of Production Research, 1-17, DOI: 10.1080/00207543.2017.1299947 
Levrat, E., Iung, B., Crespo Marquez, A., 2008. E-maintenance: review and conceptual framework, Production Planning \& Control, 19(4), 408-429.

Lim, D. and Klobas, J., 2000. Knowledge management in small enterprises, The Electronic Library, $18(6), 420-433$.

Lin, S., Gao, J., Koronios, A., 2006. A Data Quality Framework for Engineering Asset Management, Proceedings of the 1st World Congress on Engineering Asset Management (WCEAM) $11-14$ July 2006, 473- 482.

March, S. T., Scudder, G. D., 2017. Predictive Maintenance: Strategic use of IT in manufacturing organizations, Information System Frontiers, 1-15, DOI: 10.1007/s10796-017-9749-Z

MIMOSA, 2018. Machinery Information Management Open System Alliance, available at: www.mimosa.org/, accessed July 2018.

Mobley R. K., Higgins L. R., Wikoff, D. J., 2008. Maintenance Engineering Handbook, Seventh Edition, McGraw-Hill Education,

Moore, W. J., Starr, A. G., 2006. An intelligent maintenance system for continuous cost-based prioritization of maintenance activities, Computers in Industry, 57(6), 595 - 606

Muller, A., Crespo Marquez, A., Iung, B., 2008. On the concept of e-Maintenance: Review and current research, Reliability Engineering and System Safety 93, 1163-1187.

Murthy, D.N.P., Karim, M.R., Ahmadi, A., 2015, Data management in maintenance outsourcing, Reliability Engineering and System Safety 142, 100-110.

Prajapati, A., Bechtel, J., Ganesan, S., 2012. Condition based maintenance: a survey, Journal of Quality in Maintenance Engineering, 18 (4), 384-400

Ray, S.R., Jones, A., 2006. Manufacturing interoperability, Journal of Intelligent

Manufacturing, 17(6), 681-688.

Sebastian-Coleman. L., 2012. Measuring Data Quality for Ongoing Improvement: A Data Quality Assessment Framework, Newnes Publication, ISBN: 9780123977540,376 pages.

Siegel, J. 1998. OMG overview: CORBA and the OMA in enterprise computing, Communications of the ACM, 41(10), 37-43.

Tretten, P., Karim, R., 2014. Enhancing the usability of maintenance data management systems, Journal of Quality in Maintenance Engineering, 20(3), 290 - 303.

Tsang, A. H. C., 2002. Strategic dimensions of maintenance management, Journal of Quality in Maintenance Engineering, 8(1), 7-39.

Tsang, A. H. C., Yeung, W.K., Jardine, A. K.S., Leung, B.P.K., 2006. Data management 
for CBM optimization, Journal of Quality in Maintenance Engineering, 12 (1), 37 - 51.

Wandt, K., Karim, R., Galar, D., 2012. Context adapted prognostics and diagnostics, The $9^{\text {th }}$ International Conference on Condition Monitoring and Machinery Failure Prevention Technologies, 12-14 January, London, 541-550.

Wan, S., Li, D., Gao, J., Roy, R., Tong, Y., 2017. Process and knowledge management in a collaborative maintenance planning system for high value machine tools, Computers in Industry 84, 14-24.

Wang, X. V., Xu, X. W., 2013. An interoperable solution for Cloud manufacturing, Robotics and Computer-Integrated Manufacturing 29, 232-247.

Yin, R. K., 1994. Case study research: Design and methods, $2^{\text {nd }}$ Edition, Newbury Park, CA, Sage Publications, ISBN: 9780803956629,170 pages

Zhang, W., Halang, W., Diedrich, C., 2003. An Agent-based Platform for Service Integration in EMaintenance, IEEE International Conference on Industrial Technology, 10-12 December 2003. 